\title{
A CLINICAL STUDY OF RISK FACTORS ASSOCIATED WITH YOUNG PATIENTS OF MYOCARDIAL INFARCTION
}

Ashish Goel1 ${ }^{1}$ Divya Goel2, Yogesh Yadav ${ }^{3}$

${ }^{1}$ Assistant Professor, Department of Medicine, Dr. Baba Saheb Ambedkar Medical College and Hospital, Rohini, Delhi.

${ }^{2}$ Assistant Professor, Department of Radiology, Dr. Baba Saheb Ambedkar Medical College and Hospital, Rohini, Delhi.

${ }_{3}^{3}$ Associate Professor, Department of Anatomy, Dr. Baba Saheb Ambedkar Medical College and Hospital, Rohini, Delhi.

\section{ABSTRACT}

\section{BACKGROUND}

To study incidence, association and correlation of various risk factors in young patients (18 - 45 yrs.) of myocardial infarction presented to Santosh Medical College, Ghaziabad, from May 2010 to April 2011.

\section{MATERIALS AND METHODS}

50 patients of aged 18 - 45 yrs. with acute myocardial infarction were evaluated on the basis of age, sex, socioeconomic status, family history of coronary artery disease, smoking, obesity, history of hypertension, diabetes, dyslipidaemia, ECG and ejection fraction on 2D-echo.

\section{RESULTS}

Mean age of study group is $36.24 \pm 4.32$ years. Male were more affected than female with M:F ratio of 5.25:1. Prevalence of family history of coronary heart disease was 35\%. Maximum patients belonged to lower class category (52\%) followed by middle class (28\%); $55 \%$ of patients were smokers; $20 \%$ of patients were obese; $75 \%$ patients had dyslipidaemia; $25 \%$ had history of hypertension and $20 \%$ were diabetic; $64 \%$ of patients in present study had anterior wall MI, while $24 \%$ had inferior wall MI and $12 \%$ had anteroseptal wall MI; $40 \%$ of patients had mild LV dysfunction, $50 \%$ had moderate LV dysfunction and $10 \%$ had severe LV dysfunction.

\section{CONCLUSION}

The incidence of Myocardial Infarction is rising and the trend of involvement of young people are also increasing, which is possibly due to changed lifestyle, sedentary and eating habits. The maximum incidence of young myocardial infarction is in males with most in $3^{\text {rd }}$ decade of life. Dyslipidaemia and Smoking are most prevalent risk factors. High correlation was found with family history of coronary disease.

\section{KEYWORDS}

Myocardial Infarction, Risk Factors.

HOW TO CITE THIS ARTICLE: Goel A, Goel D, Yadav Y. A clinical study of risk factors associated with young patients of myocardial infarction. J. Evolution Med. Dent. Sci. 2016;5(88):6588-6591, DOI: 10.14260/jemds/2016/1489

\section{BACKGROUND}

The prevalence of Coronary Artery Disease (CAD) has progressively increased in India during the later half of the last century. Projection based on the Global Burden of Disease Study estimate that by the year 2020 the burden of atheroembolic cardiovascular disease in India would surpass that in any other region in the world.

Despite impressive strides in diagnosis and management over past three decades, acute myocardial infarction continues to be a major public health problem in industrialised world and developing countries.

Although the death rate from acute myocardial infarction has declined by about 30 percent over past decade, in

Financial or Other, Competing Interest: None.

Submission 29-09-2016, Peer Review 23-10-2016,

Acceptance 28-10-2016, Published 03-11-2016.

Corresponding Author:

Dr. Yogesh Yadav,

Associate Professor,

Department of Anatomy,

Dr. Baba Saheb Ambedkar Medical College

\& Hospital, Rohini, Delhi.

E-mail: drashishgoel@hotmail.com

DOI: $10.14260 /$ jemds/2016/1489 developed countries its development is still a fatal event in approximately one-third of the patients. ${ }^{1}$

The risk of Coronary Artery Disease in Indians is 3 - 4 times higher than White Americans and as much as 20 times higher than Japanese. ${ }^{2}$ Indians are prone as a community to Coronary Artery Disease at a much younger age and also show higher incidence of morbidity and mortality than other ethnic groups. Conventional risk factors ${ }^{3,4}$ are as important in determining the risk of Coronary Artery Disease in Indian patients, as they are in other population. In addition to these factors it is clear that other newer risk factors like S. Homocysteine, Insulin Level, S. Fibrinogen, hsCRP, Lipoprotein (a), etc. which increase the predilection of Indians to develop premature and severe Coronary Artery Disease.

The key to combat the increasing incidence of Coronary Artery Disease among Indians is the control of various risk factors by population-based strategy. So by studying the role of risk factors,5,6 we can enhance our ability to institute effective preventive and control measures.

The present study is undertaken to find out the association of various risk factors and clinical profile of Acute Myocardial Infarction in Young Patients (18 - 45 years), ${ }^{7,8,9}$ which are the 
most productive part of total population presented to Santosh Medical College, Ghaziabad.

\section{Aims and Objectives}

1. To study clinical profile of acute myocardial infarction in young patients 18 - 45 years of age.

2. To study the incidence of various risk factors in young patients with myocardial infarction.

3. To study the association and correlation of various risk factors with myocardial infarction in those patients.

\section{MATERIALS AND METHODS}

The study was conducted in Department of Medicine on 50 cases of acute myocardial infarction, if they satisfied the following selection criteria. From May 2010 to April 2011.

Patients more than 18 years and less than 45 years of age presented with complaints of chest pain, palpitation (or) breathlessness (or) a combination of these were subjected primarily to electrocardiographic studies to confirm myocardial infarction.

All patients having ST segment elevation $(>1 \mathrm{~mm}$ in inferior oriented leads (or) $>2 \mathrm{~mm}$ in anterior oriented leads) in at least two consecutive leads were considered to have myocardial infarction and then included in the study.

Detailed history and clinical examination will be done in patients satisfying the selection criteria, special stress was laid in the history on Occupation, Socioeconomic status, History of DM, PVD, HT or IHD, History of smoking or alcohol consumption, personality and life style, Family history of premature CAD or CVA in any of the first degree family members (male $<55$ years of age and female $<65$ years of age). They were screened for obesity by body mass index $\left(\mathrm{w} / \mathrm{h}^{2}\right)$.

A detailed CVS examination included presence of gallop, pericardial rub and systolic murmur. RS examination was carried out for evidence of basal crepitations and rhonchi. Patients having associated congenital or valvular heart disease were excluded.

All patients will be subjected to the following laboratory investigations:- Complete haemogram, ESR, PCV, Urine for sugar, Renal Function Tests, Liver Function Tests, Fasting lipid profile for Dyslipidaemia, Fasting Blood Sugar and Postprandial Blood Sugar for Diabetes Mellitus, ECG and chest $\mathrm{x}$-ray PA view and 2D-Echocardiography for left ventricular function and evidence of CAD.

\section{Statistical Analysis}

The groups were compared for all variables using Student's ttest to compare equality for means. The results are presented as percentage and mean \pm SD.

\section{RESULTS (Table 1)}

50 young patients ( $18-45$ yrs.) of acute myocardial infarction with average age of $36.24 \pm 4.32$ years ${ }^{10,11,12}$ were studied Maximum (84\%) were males. ${ }^{13,14}$ Youngest being $25 \mathrm{yrs}$. of age and the maximum incidence of the disease was found in $3^{\text {rd }}$ decade. Prevalence of family history of coronary heart disease was $35 \%$. No single patient had history of premature coronary artery disease in the family (i.e. CAD in male $<55$ years, female $<65$ years). ${ }^{14}$ Maximum patients belonged to lower class category (52\%) followed by middle class (28\%). Only $20 \%$ patients were from upper class; $55 \%$ of patients were smokers. ${ }^{14,15}$ They were smoking beedies or cigarettes; $35 \%$ of patients smoked more than five pack years. No female was a smoker; $20 \%$ of patients were obese and all of them were male 10,$11 ; 46 \%$ of patients lead sedentary lifestyle and $50 \%$ had type A personality. Dyslipidaemia was the most common risk factor in the present study (75\% of patients). ${ }^{13,14}$ Combined dyslipidaemia was the most common phenotype $152 \%$ of patients); 58\% had high LDL cholesterol, 36\% had low HDL cholesterol and $40 \%$ had high triglycerides; $25 \%$ had history of hypertension 11,10 and $20 \%$ were diabetic ${ }^{14,11 ;} 64 \%$ of patients in present study had anterior wall MI, while $24 \%$ had inferior wall MI and $12 \%$ had anteroseptal wall $14,10 \mathrm{MI}$. In the present study $40 \%$ of patients had mild LV dysfunction, $50 \%$ had moderate LV dysfunction and $10 \%$ had severe LV dysfunction.

\begin{tabular}{|c|c|c|c|c|c|c|c|c|c|c|c|}
\hline & & $\begin{array}{c}\text { Present } \\
\text { Study }\end{array}$ & $\begin{array}{c}\text { Brian B } \\
\text { Hoit et al } \\
\end{array}$ & $\begin{array}{c}\text { S B Siwach } \\
\text { et al }\end{array}$ & \begin{tabular}{|c|}
$\begin{array}{c}\text { Dwiwedi } \\
\text { et al }\end{array}$ \\
\end{tabular} & $\begin{array}{c}\text { P Jit Singh } \\
\text { et al }\end{array}$ & \begin{tabular}{|l|} 
Isser \\
et al
\end{tabular} & $\begin{array}{l}\text { Dani } \\
\text { et al }\end{array}$ & $\begin{array}{c}\text { H S Wassir } \\
\text { et al }\end{array}$ & $\begin{array}{c}\text { Mosseti and } \\
\text { Malacreddi }\end{array}$ & $\begin{array}{c}\text { Underwood } \\
\text { et al }\end{array}$ \\
\hline & $\begin{array}{c}\text { Total Population } \\
\text { Average age }\end{array}$ & 36.24 & 39.5 & 35.4 & 36.66 & 38.4 & 34 & - & 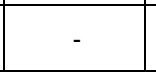 & 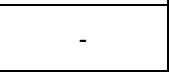 & \\
\hline & Men's Average Age & 37.2 & - & 33.1 & 36.57 & 38.15 & 39 & - & - & - & \\
\hline & $\begin{array}{l}\text { Women's Average } \\
\text { Age }\end{array}$ & 35.3 & - & 38 & 37.93 & 41.5 & 36 & - & - & - & \\
\hline & Men : Women Ratio & $5.25: 1$ & - & - & $4.0: 1$ & - & - & $4.55: 1$ & - & - & \\
\hline & $\begin{array}{c}\text { Family History of C. } \\
\text { A. D. (\%) } \\
\end{array}$ & 36 & - & - & - & - & - & 36 & 37.9 & 38.1 & \\
\hline & $\begin{array}{l}\begin{array}{l}\text { Prevalence of } \\
\text { smoking (\%) }\end{array} \\
\end{array}$ & 56 & - & - & - & - & - & 60 & 48 & - & 83.9 \\
\hline \multirow{6}{*}{$\begin{array}{c}\text { Dyslipida } \\
\text { emia }\end{array}$} & $\begin{array}{c}\text { High Total } \\
\text { Cholesterol (\%) }\end{array}$ & 24 & - & - & 41.6 & - & - & 42 & - & 47.3 & - \\
\hline & High LDL (\%) & 40 & - & - & 50 & - & - & 53.3 & - & 48.8 & - \\
\hline & $\begin{array}{l}\text { High Triglyceride } \\
(\%)\end{array}$ & 40 & - & - & 44.7 & - & - & 38 & - & 50.8 & - \\
\hline & Low HDL (\%) & 36 & - & - & 37.8 & - & - & 33 & - & 36.6 & - \\
\hline & $\begin{array}{c}\text { Prevalence of } \\
\text { Hypertension (\%) }\end{array}$ & 24 & - & 10.7 & - & 38 & - & 8 & - & - & \\
\hline & $\begin{array}{l}\text { Prevalence of } \\
\text { Diabetes (\%) }\end{array}$ & 20 & - & - & - & 11.9 & - & 10 & - & - & \\
\hline \multirow{2}{*}{\begin{tabular}{|} 
Myocardi \\
al \\
Infarction \\
- Site
\end{tabular}} & Anterior Wall (\%) & 64 & - & 72.3 & - & - & - & 66 & - & - & \\
\hline & Inferior Wall (\%) & 24 & - & 27.4 & - & - & - & 16 & - & - & \\
\hline
\end{tabular}




\section{DISCUSSION}

In our study, we have examined patients of Myocardial Infarction who are aged between 18 to 45 yrs. and other eligibility criteria for the assessment of modifiable and nonmodifiable risk factors. Youngest patient was a male of 25 years old. Most of the events in both sexes occurred in late $3 \mathrm{rd}$ decade, i.e. mean age being 36.24 .

The ratio of Male-to-Female sex ratio in our study is 5.25:1. The less incidence in young female may be due to hormonal effects, especially oestrogen and relative absence of smoking. No patient had a family history of premature coronary artery disease (i.e. CAD in male $<55$ years and female $<65$ years). However, $36 \%$ of patients had family history of coronary artery disease.

In the present study, maximum patients belonged to lower class category (52\%) followed by middle class $(28 \%)$. Only $20 \%$ patients were from upper class. This may be due to study was conducted in a hospital setup where maximum patients belonged to lower or middle socioeconomic class.

The prevalence of smoking is about 55\% in the present study and it could be concluded that smoking is a significant risk factor for premature coronary artery diseases. The prevalence of obesity is $20 \%$ in the present study. The prevalence of sedentary habits in the present study is $46 \%$. It may be because of modernisation, change in feeding habits like preference to fast foods and oily items, faddism towards vegetables. Rapid urbanisation has also changed the lifestyle of people from hard work to office work. Further, less availability of leisure hours and stress in day-to-day work prevented people from sparing time for performing physical exercise.

The prevalence of type A personality is $50 \%$ in present study. More number of type A personality patients was expected in the study, but paradoxically the number of type $\mathrm{A}$ and B personalities were equal. This may be due to the high prevalence of other risk factors in type B personality, which had influenced the result.

About $75 \%$ of patients were having dyslipidaemia in the present study. The high intake of fatty and oily feeds in the population of present study that could contribute to high incidence of dyslipidaemia in the present study. Moreover, the prevalence of diabetes mellitus was also high, which could again contribute to dyslipidaemia. In addition, in this study more stringent values are taken as cut-off to define dyslipidaemia (which is recommended now-a-days).

Prevalence of hypertension in our study is $25 \%$. Higher prevalence of other risk factors of hypertension like obesity, sedentary life habits, diabetes mellitus, dyslipidaemia, feeding habits in the present study group could be a contributing factor for the high prevalence. Also in general prevalence of hypertension is less in younger age group as compared to elderly.

A high prevalence of Diabetes Mellitus of $20 \%$ was noted in the present study. Feeding habits, higher incidence of obesity and sedentary lifestyle and probable genetic factors could contribute to the difference.
$64 \%$ of patients in present study had anterior wall MI, while $24 \%$ had inferior wall MI and $12 \%$ had anteroseptal wall MI. Anterior wall MI is more common, because LAD coronary artery is the most frequent culprit for the development of atherosclerosis. In the present study $40 \%$ of patients had mild LV dysfunction, 50\% had moderate LV dysfunction and $10 \%$ had severe LV dysfunction. The long-term prognosis of patients of myocardial infarction is much dependent upon LV function.

\section{CONCLUSION}

The incidence of Myocardial Infarction is rising in young individuals owing to change in lifestyle pattern, eating habits, more stress and workload. Incidence remained highest in males as compared to females. Highly associated risk factor in young myocardial infarction patients are dyslipidaemia and smoking. Other traditional risk factors associated with myocardial infarction like diabetes, hypertension, obesity are also very much correlated and their incidence also seems to be increasing.

\section{REFERENCES}

1. Bahl VK, Prabhakaran D, Karthikeyan G. Coronary artery disease in Indians. IHJ 2001;53:707-13.

2. Rissan HS, Kishore S, Trehan N. Coronary artery disease in young Indians-the missing link. JIACM 2001;2(3):12832.

3. Braunwald E, Loscalzo J. Ischaemic heart disease. Harrison's principle of internal medicine. 19th edn. McGraw Hill 2001:1578-611.

4. Libby P. The vascular biology of atherosclerosis in heart disease: a text book of cardiovascular medicine. $10^{\text {th }}$ edn. Braunwald E. (edr) Philadelphia, Saunders 2015:873-90.

5. Ginsberg HN, Goldberg IJ. Disorders of lipoprotein metabolism in harrison's principles of internal medicine. 19th edn. Braunwald E. (edr) McGraw Hill 2015:2435-48.

6. Egred M, Viswanathan G, Davis GK. Myocardial infarction in young adults. Postgrad Med J 2005;81(962):741-5.

7. Osula S, Bell GM, Hornung RS. Acute myocardial infarction in young adults: causes and management. Postgrad Med J 2002;78(915):27-30.

8. Kumar V, Cotran RS, Robbins SL. Basic pathology. $7^{\text {th }}$ edn. Philadelphia, Saunders 2004.

9. Hbejan K. Smoking effect on ischemic heart disease in young patients. Heart views 2011;12(1):1-6.

10. Siwach SB. Profile of young acute myocardial infarction in Haryana. JAPI 1998;46(5):424-6.

11. Singh JP. Myocardial infarction in young-a study of 42 cases. JAPI 2001;49:32.

12. Iser HS, Puri VK, Narain VS, et al. Lipoprotein (a) and lipid levels in young patients with myocardial infarction and their first degree relatives. IHJ 2001;53(4):463-6.

13. Dwiwedi S, Dwiwedi G, Sharma S, et al. Coronary artery disease in young: heredofemilial or faulty life style or both. JIACM 2000;1(3):245-51. 
14. Dani SI, Ghosh SB, Prajapati JS, et al. Clinical and coranary angiographic profile of coronary artery disease in a young Gujarati population. IHJ 2003.
15. Garg KC, Negi NS. Acute myocardial infarction in young adults. JAPI 1987;35(4):281-4. 